\title{
Poplar plywood resistance to wood decay agents: efficacy of some protective treatments in the light of the standard ENV 12038
}

\author{
Roberto Zanuttini ${ }^{a *}$, Giovanni Nicolotti ${ }^{\mathrm{b}}$ and Corrado Cremonini ${ }^{\mathrm{a}}$ \\ a AGROSELVITER Dept., University of Torino, Via L. da Vinci 44, 10095 Grugliasco, Italy \\ b DI.VA.P.R.A. - Plant Pathology, University of Torino, Via L. da Vinci 44, 10095 Grugliasco, Italy
}

(Received 11 September 2001; accepted 12 April 2002)

\begin{abstract}
This work is a further contribution to the knowledge of the effects of fungal decay on poplar plywood potentially used in exposure conditions of high humidity. The influence of some surface and edge coatings on MUF glued panels, made of veneers of the poplar clone 'I214', has been evaluated against the attack of wood decay fungi, according to the test method provided by CEN/TC38, now ENV 12038. The residual bonding quality has also been verified (EN 314). All specimens showed a high level of biodegradation. The best protection system seems to be the combination of treating the surface and painting the edges of the panels, while the surface treatments alone were less effective. The article also points out that the test method used is not the most suitable for evaluating the biological durability of plywood, considering its real use in exterior conditions.
\end{abstract}

poplar / plywood / fungal decay / biological durability / protective treatment

Résumé - Résistance du contreplaqué de peuplier aux dégâts dus aux champignons : efficacité des traitements de protection en relation à la norme ENV 12038. Ce travail est une contribution à la connaissance du comportement du contreplaqué de peuplier face aux dégâts dûs aux champignons, en considérant son utilisation dans une exposition caractérisée par une forte humidité. L'influence de la protection sur la surface et sur le bord des panneaux (collés avec une résine MUF) réalisés avec des placages déroulés provenant du clone 'I-214', a été évaluée contre l'attaque biologique des basidiomycètes en suivant la méthode d'essai ENV 12038. La qualité du collage résiduelle a été aussi vérifiée (EN 314). Tous les échantillons ont subi une biodégradation élevée. Le meilleur système de protection semble être une combinaison entre le traitement de surface et la peinture des bords des panneaux, alors que le traitement de surface seul est peu efficace. L'article montre aussi que la méthode d'essai employée n'est pas vraiment utilisable pour évaluer la durabilité biologique du contreplaqué, en considération de son emploi dans des conditions extérieures.

peuplier / contreplaqué / pourriture / durabilité / préservation

\section{INTRODUCTION AND SCOPE}

The present work is more in-depth study of a previous one [9] concerning the resistance of poplar plywood of the clone 'I-214' against degradation caused by wood decay basidiomycetes.

The results of that research, achieved in accordance with a test protocol of CEN/TC38 which represent the initial draft of the ENV 12038 on test pieces glued with a PMUF (phenolmelamine-urea-formaldehyde) resin-based mixture, showed a correlation between the panel composition and the mass loss determined by the fungal alteration: in panels composed of thicker veneers $(2.6 \mathrm{~mm})$ the mean mass loss value was higher than that registered for the plywood made of thinner ones $(1.1 \mathrm{~mm})$ (table I). From the afore mentioned study, solid wood test pieces and plywood of the same nominal thickness, made of 1.1 and $1.5 \mathrm{~mm}$ thick veneers, underwent lower reduction of mass than the panels made both with 2.1 and $2.6 \mathrm{~mm}$ thick veneers.

Another result achieved concerned a statistically significant correlation between the mass loss of test pieces and their mechanical resistance in the screw withdrawal test.

For a better understanding of the problem of the plywood durability, it is in any case useful to refer to the European standardization context related to the biological durability of wood and wood-based panels. The EN standards consider that, in case of a possible attack by wood destroying organisms, a solid wood should be used, selected from species having an adequate biological durability or, when necessary, adopting a suitable preservative treatment. Within this context, EN 350-1 acts as a guideline for the determination and classification of the natural durability of solid wood against the attack of wood destroying organisms. Part 2 of the same standard illustrates

* Correspondence and reprints

Tel.: +39 011 6708644; fax: +39 011 6708734; e-mail: roberto-zanuttini@ unito.it 
Table I. Mean percentage ( \pm standard deviation) of dry mass loss of poplar (clone 'I-214') plywood made of layers of different thickness (from Nicolotti and Zanuttini, op. cit).

\begin{tabular}{ccccc}
\hline \multirow{2}{*}{ Decay agent } & $\mathbf{1 . 1}$ & $\mathbf{1 . 5}$ & $\mathbf{2 . 1}$ & $\mathbf{2 . 6}$ \\
\cline { 2 - 5 } Thickness of veneer $(\mathbf{m m})$ \\
\hline $\begin{array}{c}\text { Pleurotus } \\
\text { ostreatus }\end{array}$ & $2.9( \pm 1.7)$ & $3.6( \pm 1.3)$ & $5.2( \pm 2.3)$ & $10.3( \pm 4.0)$ \\
\hline $\begin{array}{c}\text { Coniophora } \\
\text { puteana }\end{array}$ & $31.2( \pm 2.7)$ & $41.4( \pm 3.8)$ & $46.8( \pm 3.5)$ & $47.7( \pm 1.6)$ \\
\hline
\end{tabular}

the principles regarding the durability and impregnability of the most important European wood species. Finally, EN 335 outlines five different biological hazard classes with their relevant requirements of natural durability, with respect to the service conditions of solid wood. In this context, plywood is an example of a wood-based panel whose requirements for the use in outdoor conditions are adequately stated, but for which the biological durability is not easily assumed. In other words, data on biological durability and related test method are not available for wood-based products while they are for solid wood [5].

The guidance on factors affecting the durability of plywood in exterior conditions and on requirements for its correct use and maintenance operations which may be necessary for that type of exposure can be found in ENV $1099^{1}$ and EN 335-3. Therefore, ENV 1099, which is the only document finalized to the selection of plywood best-suited in terms of biological durability for a specific exposure and biological hazard class, is based again on the EN 460 indications on the durability of solid wood. The above standard, in fact, examines the classification of the natural durability of solid wood and correlates it with the durability and impregnability of the wood species used to make the panel, considering the presence of sapwood and heartwood, the influence of the veneer's thickness, the type of glue mixture and any possible preservation substances. This document, while stating that there are potential differences in the biological durability of the adhesive, does not refer to any standard or assessment procedure about resistance to biodegradation of the adhesive mixture, and does not take into account any surface treatment on the panel faces or edges $^{2}$. Besides, as regards the action of wood decay agents, the document gives a rough idea of the natural durability of the woods most suitable for making plywood in a certain hazard class of biological attack [2, 4].

It should be noted that the use of a perishable wood species characterized by a low natural durability is not allowed in the highest hazard classes. There are however, many plywoods made from these species currently used in outdoor conditions [10]. Birch plywood made from a wood species of biological durability comparable with that of poplar is such an example. This plywood, with adequate surface protection and composition is regularly used in the transport and buildings sectors and most others exterior applications. In this context it can be supposed that also protected plywood made with veneers of low natural durability, used under hazard class 3 conditions requires no preservative treatments. Many times the service life of such plywood is more related to its bonding quality than to the impact of wood decay [3].

Based on the above findings and considerations, this work aims to assess the influence of protecting the panel surface and, in particular:

1. to check the efficacy of water-proofing finishes and treatments;

2. to check possible correlation between mass loss and the residual bonding quality, measured in terms of shear strength;

3 . to validate the applicability of the reference test protocol as a tool to predict the suitability of the use of plywood in specified exposure conditions.

The experimentation performed is therefore intended to increase the technical knowledge of this widely used woodbased panel regarding fungal alteration, not merely its biological durability as defined in ENV 12038.

\section{MATERIALS AND METHODS}

The plywood panels for this research were manufactured using veneers made of 'I-214' poplar clone bonded with a MUF (melamineurea-formaldehyde) resin mixture suitable for gluing wood-based panels for use in humid and exterior conditions (bonding classes 2 and 3, complying with EN 314-2), where there is a high risk of damage by wood-rotting agents (hazard classes 2 and 3 of EN 335-3) [1, $6]$. The adhesive, commonly used in the Italian plywood manufacturing, was acquired directly from the producer. It contains about $22 \%$ of melamine, with a dry residue of $63 \pm 1 \%$, a molar ratio $(\mathrm{M}+\mathrm{U}) / \mathrm{F}$ of $1: 1.2$ and $0.2 \%$ of free formaldehyde (i.e., meeting the requirements for Class A of formaldehyde emission according to EN 1084).

The methods for preparing the test pieces, their conditioning, the fungal culture and the determination of mass loss have been those given in the 1992 draft of ENV 12038 from CEN/TC38 3 . The basidiomycetes used for testing were Coniophora puteana (= Coniophora cerebella) (Schumacher ex Fries) - strain BAM Ebw 15, agent of brown rot and Pleurotus ostreatus (Jaquin ex Fries) - strain FPRL $40 \mathrm{C}$, agent of white rot. The virulence of $C$. puteana and $P$. ostreatus strains was tested on 6 Scots pine wood blocks and 6 beech blocks, respectively.

\subsection{Panel composition and preparation of test pieces}

Panels with size of $60 \times 60 \mathrm{~cm}$, nominal thickness of $18 \mathrm{~mm}$ and fully consisting of 1.1 and $2.6 \mathrm{~mm}$ veneers, therefore with 17 and 7

\footnotetext{
1 The CEN/TC 112 "Wood-based panels" is the Technical Committee responsible for the production of European standards related to the Construction Products Directive 89/106/ECC. The laboratory test method adopted to evaluate the biological durability of wood-based panels to fungal decay is based on the co-operation with the above TC and CEN/TC 38 "Durability of wood and wood related materials." Recently, CEN/TC 112 supported the proposal of revision of ENV 12038 and ENV 1099 and invited CEN/TC 38 to develop a research program in order to better characterize the biological durability of plywood and to provide a technical support for linking the end uses of the product with the hazard classes given in EN 335-3.

2 At present there is no available official standard for the durability and resistance to various biodegradation agents of synthetic adhesives used for gluing the wood-based panels. The DIN 68705 on "bonding quality of plywood" provides for the use of glue mixtures containing preservatives, without however making reference to methods for testing the fungicidal characteristics of the adhesives.

3 We decided to use this version because we didn't want to change the methodology during the whole development of the research (started in 1992). Beside, we realized that unimportant changes were introduced in the following drafts of the standard.
} 
layers respectively, were made at laboratory level. Four different types of uncovered panels and four protected with surface treatment and painted edges were produced, for a total of 6 different combinations, as given below:

\begin{tabular}{ll}
\hline FP+EP & Filmed Plywood (overlaid with impregnated film) + Edge \\
& Protection (with acrylic paint) \\
FP & Filmed Plywood \\
RCP+EP & Resin Coated Plywood + Edge Protection \\
RCP & Resin Coated Plywood \\
UP+EP & Uncovered Plywood + Edge Protection \\
UP & Uncovered Plywood (as control) \\
\hline
\end{tabular}

All the panels were glued with the same adhesive mixture made up of 100 parts of MUF resin, 8 parts of coconut flour, 2 parts of wheat flour for industrial use, 2 parts of calcium carbonate and 8 parts of $25 \% \mathrm{NH}_{4} \mathrm{Cl}$ solution (acting as hardener). The various components were mixed, by a mechanical stirrer, in a polypropylene beaker. The quantity of the mixture spread during the panel lay-up was between 300 and $340 \mathrm{~g} \mathrm{~m}^{-2}$ for a double glue-line. Surface treatment was done, during the subsequent pressing operation (table II), partly using a film impregnated with $160 \mathrm{~g} \mathrm{~m}^{-2}$ of phenolic resin and partly coating the panel with a layer of adhesive mixture (the same type as that used for bonding the single layers, but with the addition of ferrous oxides for coloring purposes) by spreading a total amount of about $100 \mathrm{~g} \mathrm{~m}^{-2}$ on both faces of the panel. The edges were protected by paint made of fine acrylic resins dispersed in aqueous solution, with low toxicity for higher organisms. Its main characteristics are given in table III.

A series of 12 test pieces measuring $150 \times 55 \times 18 \mathrm{~mm}$ was prepared for each type of panel, for a total of 144 test pieces. The above size, which represents a deviation with respect to the $50 \times 50 \mathrm{~mm}$ mentioned in the reference standard, was selected in order to be able to determine the bonding quality by tension shear test complying with EN 314. The possible size influence of the test pieces in relation to the fungal activity will be evaluated in the discussion. Within each series, the test pieces were divided into:

- test pieces inoculated with P. ostreatus;

- test pieces inoculated with C. puteana;

- control test pieces;

- test pieces to check the initial moisture content;

- test pieces to check the final moisture content.

\subsection{Pre-treatment of the test pieces}

Prior to inoculation, the test pieces were subjected to an accelerated aging cycle as EN 84. This procedure was used because, it was supposed to be the most severe and appropriate to leach the formaldehyde from the adhesive and to simulate high humidity exposure conditions.

The test pieces were impregnated under vacuum (at 40 mbar for $20 \mathrm{~min}$ ) with deionised water, then kept in this medium for 14 days, during which the water was changed 9 times. They were further conditioned in a climatic cell for four weeks at a temperature of $20 \pm 1{ }^{\circ} \mathrm{C}$ and relative humidity of $65 \pm 5 \%$, and then sterilized with $\gamma$ rays (1.5 Mrad) using Cobalt-60 radioisotopes.

\subsection{Test piece inoculation}

The plywood test pieces were placed in culture vessels with a capacity of $600 \mathrm{~mL}$ containing:

- $120 \mathrm{~mL}$ of growth medium for C. puteana and $130 \mathrm{~mL}$ for P. ostreatus $\left(40 \mathrm{~g} \mathrm{~L}^{-1}\right.$ of malt extract agar containing $0.9 \pm 0.3 \% \mathrm{~N}$, $950 \mathrm{~mL}$ of $\mathrm{KCl}$ solution $0.1 \mathrm{~N}, 50 \mathrm{~mL}$ of $\mathrm{HCl} 0.1 \mathrm{~N}$ );
Table II. Pressing parameters used in the production of the various types of plywood.

\begin{tabular}{lcccc}
\hline & & \multirow{2}{*}{$\begin{array}{c}\text { Untreated } \\
\text { Process parameters }\end{array}$} & Unit & \multicolumn{2}{c}{ Surface-treated panels } \\
\cline { 4 - 5 } & & & $\begin{array}{c}\text { with phenolic } \\
\text { film overlaying }\end{array}$ & $\begin{array}{c}\text { with resin } \\
\text { coating }\end{array}$ \\
\hline Pressure & $\mathrm{kg} \mathrm{cm}^{-2}$ & 8 & 15 & 12 \\
Temperature & ${ }^{\circ} \mathrm{C}$ & 90 & 95 & 90 \\
Time & $\min$ & 12 & 15 & 8 \\
\hline
\end{tabular}

Table III. Physical-chemical features of the acrylic paint used for protecting edges.

\begin{tabular}{lcc}
\hline \multicolumn{1}{c}{ Characteristics } & Unit & Values \\
\hline Specific weight & $\mathrm{g} \mathrm{cm}^{-3}$ & 1.340 \\
Dry weight & $\%$ & $57.5 \pm 0.2$ \\
Spreading rate & $\mathrm{g} \mathrm{cm}^{-2}$ & 0.015 \\
Dry time & $\mathrm{min}$ & 30 \\
\hline
\end{tabular}

$-250 \mathrm{~mL}$ of an inert substrate of vermiculite completely colonized by the fungal mycelium;

- Scots pine feeder blocks for C. puteana cultures and beech feeder blocks for $P$. ostreatus cultures.

The control test pieces were placed in vessels containing only vermiculite and deionised water. All the culture vessels were then left in a climatic chamber for 16 weeks at a temperature of $22 \pm 1{ }^{\circ} \mathrm{C}$ and $70 \pm 5 \%$ of relative humidity. Six Scots pine and beech virulence control blocks were inoculated in the same climatic chamber to verify the virulence of $C$. puteana and P. ostreatus, respectively. At the end of the incubation period the external mycelium were thoroughly cleaned off the test pieces that have been again conditioned and weighed to determine the final conditioned mass.

\subsection{Determination of the dry mass loss}

The dry mass of the test pieces and the relative moisture factor $F_{i}$ were determined for the control of each series as follows:

$$
\mathrm{F}_{\mathrm{i}}=1-\frac{\left(\mathrm{m}_{0}-\mathrm{m}_{1}\right)}{\mathrm{m}_{0}}
$$

where: $\mathrm{F}_{\mathrm{i}}=$ initial moisture factor; $\mathrm{m}_{0}=$ conditioned mass; $\mathrm{m}_{1}=$ initial oven dry mass.

Having determined the mean $F_{i}$ for each series, the oven dry mass $\left(\mathrm{m}_{1}\right)$ of the equivalent set of test specimen was calculated using the following formula:

$$
\mathrm{F}_{\mathrm{i}} \times \mathrm{m}_{0}=\mathrm{m}_{1} .
$$

The percentage of dry mass loss due to fungal degradation was then calculated:

$$
\text { Final loss of dry mass }=\frac{\left(\mathrm{m}_{1}-\mathrm{m}_{3}\right)}{\mathrm{m}_{1}} \times 100
$$

where $\mathrm{m}_{3}=$ final dry mass.

Since the bonding quality is a characteristic parameter of plywood, its residual strength was determined by a test carried out in compliance with EN 314 after immersion of the test pieces for 24 hours in cold water (pre-treatment 5.1.1 as indicated in the same standard). To do this, two test pieces were taken from all the inoculated and control specimens. These, measuring $150 \mathrm{~mm} \times 25 \mathrm{~mm}$, 
were subjected to tension shear applied in a middle area of $25 \times$ $25 \mathrm{~mm}$ with a testing machine having a maximum capacity of $50 \mathrm{kN}$ and accuracy of $\pm 1 \%$. The shear test was done with a load bar displacement speed of $1 \mathrm{~mm} /$ minute. The shear strength was calculated with the following formula:

$$
\mathrm{R}=\frac{\mathrm{F}_{\max }}{\mathrm{S}} ;\left[\mathrm{N} \mathrm{mm}^{-2}\right]
$$

where: $\mathrm{F}_{\max }=$ maximum tension, in $\mathrm{N} ; \mathrm{S}=$ shear area of the test piece $(25 \times 25 \mathrm{~mm})$.

\section{RESULTS AND DISCUSSION}

The virulence test carried out with $C$. puteana induced a mass loss of $40.3 \pm 6.9 \%$ (S.D.) on Scots pine blocks while P. ostreatus caused a mass loss of $23.5 \pm 5.6 \%$ (S.D.) on beech blocks. From the ENV 12038 point of view, both fungi were suitable to carry out the test, causing a mass loss over than the required threshold of $20 \%$. Nevertheless, $P$. ostreatus showed virulence lower than $C$. puteana with a variability of about $\pm 20 \%$ in the degradation activity that actually put it at the borderline. Moreover, $P$. ostreatus showed a high variability also during the test on plywood, both among the different protective treatments and within the same treatment. C. puteana, instead, showed higher values of mass loss but less variability considering the solid wood blocks to the plywood specimen. From the third week of fungal exposure, the test pieces inoculated with $C$. puteana showed deformations and alterations in the surface layer, attributable partly to the hygrometric variations and partly to the attack by the fungal agent. Figure 1 gives a summary view of the percentage of the dry mass loss registered.

In respect to the previous work, and in contrast to what would be expected, for $P$. ostreatus the test pieces made of thin veneers $(1.1 \mathrm{~mm})$ recorded higher mass loss than those made of thicker veneers $(2.6 \mathrm{~mm})$. In particular, the $P$. ostreatus inoculated test pieces showed a mean mass $\operatorname{loss}^{4}$ of $5.8 \%$ for those made of $1.1 \mathrm{~mm}$ thick veneers and $4.0 \%$ for those made of $2.6 \mathrm{~mm}$. Considering only the unprotected test pieces the mass losses were respectively $4.6 \%$ and $2.9 \%$ for the two compositions. These discrepancies may be partially explained by the different chemical composition of the two adhesives used. In this work the resin was a MUF (melamine-urea-formaldehyde) having a similar ratio of free formaldehyde with respect to the PMUF (phenol-melamine-urea-formaldehyde) used in the previous research which was also characterized by a high percentage of free phenol (table IV $)^{5}$. The presence of free formaldehyde and its release from the glue line had initially let us suppose that it was effective as a fungicide. But also the high toxicity of the free phenol must not be ignored [7]. In fact, wood species characterized by a high concentration of natural phenolic substances in the heartwood portion, as for example the tannins, may considerably increase the resistance to fungal decay. In this case, the mass loss determined by fungal attack is inversely related to the amount of free phenol. As shown in some studies on the durability of LVL panels against white rot
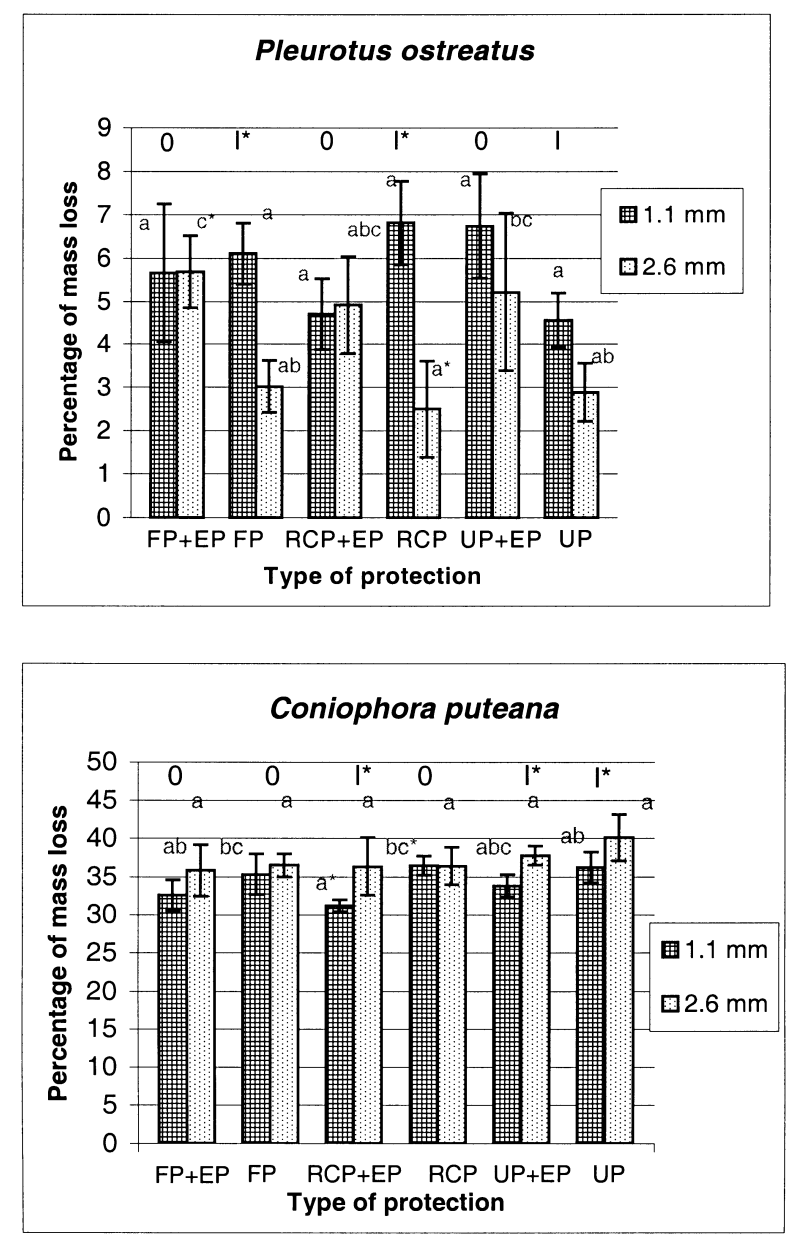

Figure 1. Percentage mass loss of test pieces from plywood made of $1.1 \mathrm{~mm}$ and $2.6 \mathrm{~mm}$ thick veneers, inoculated with $P$. ostreatus (above) and C. puteana (below). Values followed by different letters differ significantly $(P<0.05)$ or highly significantly $(P<0.01)$ (ANOVA, Tukey HSD test).

$0=$ not significant $\mathrm{I}=$ significant $(P<0.01) ; *$ = highly significant $(P<0.01)$.

$\mathrm{FP}+\mathrm{EP}=$ Filmed Plywood (overlaid with impregnated film) + Edge Protection (with acrilic paint); FP = Filmed Plywood; $\mathrm{RCP}+\mathrm{EP}=$ Resin Coated Plywood + Edge Protection; $\mathrm{RCP}=$ Resin Coated Plywood; UP + EP = Uncovered Plywood + Edge Protection; UP = Uncovered Plywood (as control).

agent (Coriolus versicolor), this phenol fraction may be a limiting factor to the degrading action of the basidiomycetes [8].

Therefore the lower mass loss for the plywood composed with thin veneers $(1.1 \mathrm{~mm})$ registered in the past may not be due to a physical effect (barrier) of the glue line or to the action of formaldehyde but to the presence of free phenol. That PMUF adhesive is no longer on the market because the

\footnotetext{
${ }^{4}$ Mean value for all types of plywood examined.

5 The presence of free phenol in the PMUF liquid resin has been confirmed by the ${ }^{13} \mathrm{C}-\mathrm{NMR}$ analysis.
} 
Table IV. Chemical analysis of the liquid PMUF and MUF resins.

\begin{tabular}{lcc}
\hline & \multicolumn{2}{c}{ Percentage in weight } \\
\hline \multirow{2}{*}{ Urea } & PMUF & MUF \\
Nitrogen & 41.4 & 27.9 \\
Free phenol & 19.1 & 36.1 \\
Free formaldehyde & 0.6 & 0.0 \\
$\mathrm{pH}$ & 0.2 & 0.2 \\
\hline
\end{tabular}

considerable leaching of phenols was in violation of the limits of modern environmental legislation. It is possible to suppose that a similar adhesive system could guarantee higher protection for the panel just for a period of a few years, but then, due to the leaching of the phenolic component decrease over time. Analyzing the different plywood protections, the combination of resin coating and edge painting did not lead to a significant improvement in the level of mass loss than the resin coating alone. Contrasting results were obtained in the test pieces inoculated with $P$. ostreatus. Both surface-treated and/or painted edge test pieces made with $1.1 \mathrm{~mm}$ thick veneers and those made with $2.6 \mathrm{~mm}$ veneers recorded a higher mass loss than the uncovered ones. Considering the lower degradation activity of $P$. ostreatus towards the test pieces of plywood in comparison with solid wood blocks, it can be supposed that, besides the virulence variability as a main driving force for explaining the differences in mass loss, some other factors could have influenced the activity of this white rot fungus, for instance: (i) a "size effect" connected to the bigger dimensions of the plywood specimen, in respect to the solid wood blocks, and (ii) a different degradability between solid wood beech and poplar plywood, also due to the presence of the glue layers.

The test pieces inoculated with $C$. puteana showed a similar trend, in terms of mass loss, to that of the previous study: plywood made of thicker veneers recorded a higher mass loss than those made of thin layers. For these test pieces the mean mass $\operatorname{loss}^{4}$ was $34.3 \%$ and $37.2 \%$, for the $1.1 \mathrm{~mm}$ and $2.6 \mathrm{~mm}$ compositions, respectively. Analyzing the single groups of data, the mass loss of the unprotected test pieces inoculated with $C$. puteana was respectively $36.2 \%$ and $40.1 \%$ for the two compositions. The difference in mass loss between the pieces made of $1.1 \mathrm{~mm}$ thick veneers, overlaid with phenolic film and painted edges (FP+EP) and the uncovered ones (UP) was slightly lower than that shown with the resin coated test pieces with painted edges $(\mathrm{RCP}+\mathrm{EP})$ with respect to the same control specimen (UP). More precisely, the above difference in the first case was $-3.6 \%$, while for the second it was $-5.0 \%$. The test pieces made of $2.6 \mathrm{~mm}$ thick veneers with surface and edges protection also recorded a lower mass loss than those uncovered and without edge protection. In these, the difference in mass loss between the phenolic film-faced test pieces with painted edges (FP+EP) and the uncovered ones (UP) was $-4.3 \%$, while for the resin coated test pieces with painted edges $(\mathrm{RCP}+\mathrm{EP})$ it was $-3.8 \%$.
Apart from the variable results obtained with $P$. ostreatus, it clearly emerges that, in terms of mass loss, any of the examined protective treatment noticeably reduced the biodegradation with respect to the value registered with the control specimen and to the $3 \%$ threshold indicated by the test protocol ${ }^{6}$. In any case, the analysis of the results showed that test protocol used is not suitable for clearly detecting the durability of plywood; the solutions adopted for affecting the above property of the panel do not appear sufficiently discriminating and it seems too severe in respect to the real exposure conditions of the product. This is especially true for the specimen inoculated with C. puteana, with a higher than $30 \%$ mean values mass loss resulted in their complete degradation at the end of the test. Similar levels of biological degradation do not have any real correspondence in the use of plywood in uncovered outdoor conditions. Moreover, the ENV 12038 is applicable to raw wood-based panels made with normal or preservativeadded adhesive mixture, and was not developed for being applied to the panels with protected surfaces.

As for the residual bonding quality of the plywood, the attempt to quantify the level of degradation by rot agents determining the shear strength of the glue line cannot be considered satisfactory. Only the test pieces inoculated with $P$. ostreatus have been suitable for testing the residual bonding quality, since those inoculated with $C$. puteana were degraded to such an extent that tension shear testing was not feasible. The residual strength of the glue-lines gave the results reported in table $V$. Data on the residual bonding quality after inoculation show a high level of variability inside the different panel types. Since the panels were handmade in the laboratory, it is possible that some irregularities in the spreading of the adhesive mixture could have affected the bonding quality resulting in lower values than those of the uninoculated specimen.

Equally it is difficult to assess the contribution due to the destructive action of the basidiomycetes with respect to the accelerated aging of the glue-line, and therefore to the hydrolysis exerted by the artificial aging process (EN 84) to which the test pieces were subjected prior to inoculation. It should finally be underlined that all the $P$. ostreatus inoculated test pieces registered a shear strength higher than $1 \mathrm{~N} \mathrm{~mm}^{-2}$, value which, according to EN 314, corresponds to an acceptable bonding quality avoiding the need to determine the percentage of the wood fiber failure. Based on the results obtained, it thus seems that the destructive action was limited to the veneers and did not affect the glue-line. We emphasize however that, lacking the veneer integrity, the cohesion among the layers is weakened or compromised.

\section{CONCLUSIONS}

The main aim of this work was to increase the limited knowledge on the actual resistance of poplar plywood ('I-214' clone) to degradation by wood decay agents and to supply, at least partially, suitable indications for the possible use of the panels in exterior conditions. Considering that poplar as a solid wood presents a low natural durability, the use of protections

\footnotetext{
6 The ENV 12038 does not consider "fully resistant to attack by wood-rotting basidiomycetes" a test product which records a mean mass loss greater than $3 \%$.
} 
Table V. Glue line shear strength for test pieces made of 1.1 (above) and $2.6 \mathrm{~mm}$ (below) thick veneers. Tables show the comparison between test pieces inoculated and not inoculated with $P$. ostreatus. Results are expressed in $\mathrm{N} \mathrm{mm}^{-2}$ as mean values ( \pm standard deviation). Values followed by different letters differ significantly $(P<0.05)$ or highly significantly $(P<0.01)$ (ANOVA, Tukey HSD test).

\begin{tabular}{|c|c|c|c|c|}
\hline & Type of panel a & $\begin{array}{l}\text { Inoculated } \\
\text { test pieces }\end{array}$ & $\begin{array}{l}\text { Not-inoculated } \\
\text { test pieces }\end{array}$ & $\begin{array}{c}\text { Significance } \\
\text { inoculated/ } \\
\text { not inoculated }\end{array}$ \\
\hline $\mathrm{FP}+\mathrm{EP}$ & Plywood overlaid with phenolic film + acrylic protected edges & $2.2( \pm 0.3) \mathrm{a}^{*}$ & $2.5( \pm 0.1) \mathrm{a}$ & 0 \\
\hline FP & Plywood overlaid with phenolic film & $2.2( \pm 0.2) \mathrm{a} *$ & $2.8( \pm 0.3) \mathrm{ab}$ & I * \\
\hline $\mathrm{RCP}+\mathrm{EP}$ & Resin coated plywood + acrylic protected edges & $2.1( \pm 0.2) \mathrm{a} *$ & $2.7( \pm 0.1) \mathrm{ab}$ & I * \\
\hline $\mathrm{RCP}$ & Resin coated plywood & $2.2( \pm 0.4) \mathrm{a}^{*}$ & $2.7( \pm 0.2) \mathrm{ab}$ & 0 \\
\hline $\mathrm{UP}+\mathrm{EP}$ & Untreated plywood + acrylic painted edges & $2.4( \pm 0.3) \mathrm{a}^{*}$ & $3.3( \pm 0.1) b$ & $\mathrm{I} *$ \\
\hline UP & Untreated plywood (control) & $2.9( \pm 0.2) b *$ & $3.0( \pm 0.5) \mathrm{ab}$ & 0 \\
\hline \multicolumn{5}{|c|}{ a) Test pieces made of $1.1-\mathrm{mm}$ thick veneers. } \\
\hline & Type of panel ${ }^{b}$ & $\begin{array}{l}\text { Inoculated } \\
\text { Test pieces }\end{array}$ & $\begin{array}{l}\text { Not inoculated } \\
\text { test pieces }\end{array}$ & $\begin{array}{c}\text { Significance } \\
\text { inoculated/ } \\
\text { not inoculated }\end{array}$ \\
\hline $\mathrm{FP}+\mathrm{EP}$ & Plywood overlaid with phenolic film + acrylic painted edges & $2.3( \pm 0.3) \mathrm{b} *$ & $1.9( \pm 0.3) \mathrm{a}$ & 0 \\
\hline FP & Plywood overlaid with phenolic film & $2.0( \pm 0.6) \mathrm{ab}$ & $2.1( \pm 0.7) \mathrm{a}$ & 0 \\
\hline $\mathrm{RCP}+\mathrm{EP}$ & Resin coated plywood + acrylic painted edges & $1.5( \pm 0.3) \mathrm{a} *$ & $1.5( \pm 0.5) \mathrm{a}$ & 0 \\
\hline $\mathrm{RCP}$ & Resin coated plywood & $1.8( \pm 0.3) \mathrm{ab}$ & $1.9( \pm 0.2) \mathrm{a}$ & 0 \\
\hline $\mathrm{UP}+\mathrm{EP}$ & Untreated plywood + acrylic painted edges & $2.0( \pm 0.5) \mathrm{ab}$ & $1.5( \pm 0.6) \mathrm{a}$ & 0 \\
\hline UP & Untreated plywood (control) & $1.9( \pm 0.6) \mathrm{ab}$ & $2.3( \pm 0.7) \mathrm{a}$ & 0 \\
\hline
\end{tabular}

b) Test pieces made of 2.6-mm thick veneers.

such as surface treatment and edge painting, both of which in practice should preserve plywood from alteration, has been assessed. For the plywood specimen inoculated with $P$. ostreatus, the combination of resin coating and edge painting did not lead to a significant improvement in the level of protection than the resin coating alone. According to the results obtained on the test pieces inoculated with $C$. puteana, the best protection system seems to be the combination of surface protection with edge painting. The attempt to quantify the level of degradation of the plywood by rot agents determining the residual shear strength of the glue line cannot be considered satisfactory.

The work carried out does not claim to be exhaustive. Nonetheless it focuses the attention on the need to find an alternative test protocol taking into account not only the biological durability of the solid wood concerned. In fact, clearly emerges the need to develop and validate an accelerated laboratory fungal test method for predicting the suitability of plywood with different composition and surface protections, to meet hazard class 3 requirements. This testing protocol should give results in shorter times and be more in line with the real situations of the use of panels in outdoor conditions. Within the current evolution of the European standardization framework, a new approach should be followed in order to find a more adequate testing method that differs from the present one, which is exclusively based on the activity of basidiomycetes.

Moreover, it could be useful to integrate the new method with mechanical testing. In fact, wood decay determined by biological attack and reduced mechanical properties of the product should be evaluated not only in terms of its mass loss. Finally, it would be interesting if this method could supply indications about the service life of the product in terms of bio- logical durability, meaning the period within which the physical and mechanical properties of a plywood would remain adequate for its intended use and to establish for each coating or protection systems a "minimum effective duration".

A parallel field of investigation could be the use and efficacy of fungicides in the adhesive mixture, in particular for plywood when its surface is not treated or painted.

\section{REFERENCES}

[1] Anselmi N., Govi G., Patologia del legno, Edagricole, Bologna, 1996.

[2] Baldassino N., Zanon P., Zanuttini R., Prodotti a base di legno per gli impieghi strutturali: il compensato di pioppo italiano, Ed. Assopannelli, 1995.

[3] Biblis E.J., Effect of weathering on surface quality and structural properties of six species of untreated commercial plywood siding after 6 years of exposure in Alabama, Forest Prod. J. 50 (1999) $47-50$.

[4] Blanchette R., Obst J.R., Hedges J., Resistance of hardwood vessels to degradation by white rot basidiomycetes, Can. J. Bot. 66 (1988) 1840-1847.

[5] Foliente G.C., Leicester R.H., Wang C., Mackenzie C., Cole I., Durability design for wood construction, Forest Prod. J. 52 (2002) $10-19$.

[6] Gambetta A., Orlandi E., Sulla preservazione del legno messo in opera all'aperto, Contributi scientifico pratici, Vol. XXX CNR Istituto per la Ricerca sul Legno, Firenze, 1982.

[7] Henglerth G.H., Decay resistance of plywood bonded with various glues, Forest Products Research Society, Madison WI, USA, Vol. 4 (1950) 248-253.

[8] Marchal R., La coupe du bois par déroulage: du processus au procédé. Document de synthèse pour l'habilitation à diriger des recherches. Université de Montpellier 2, (1999) 106-114. 
[9] Nicolotti G., Zanuttini R., Resistenza del compensato di pioppo ad incollaggio PMUF alla degradazione indotta da funghi lignivori: indagini preliminari sull'influenza della composizione del pannello, Legno, Cellulosa, Carta. 3 (1996) 2-10.

[10] Smulski S., Durability of energy-efficient wood-frame house, Forest Prod. J. 49 (1999) 8-15.

\section{NORMATIVE REFERENCES}

EN 84 Wood Preservative - Accelerated ageing of treated wood prior to biological testing - Leaching procedure.

EN 314-1 Plywood - Bonding Quality - Part 1: Tests methods.

EN 314-2 Plywood - Bonding Quality - Part 2: Requirements.

EN 335-1 Durability of wood and wood-based products. Definition of hazard classes of biological attack - Part 1: General.
EN 335-3 Durability of wood and wood-based products. Definition of hazard classes of biological attack - Part 3: Application to woodbased panels.

EN 350-1 Durability of wood and wood-based products. Natural durability of solid wood. Part 2: Guide to the principles of testing and classification of the natural durability of wood.

EN 460 Durability of wood and wood-based products. Natural durability of solid wood. Guide to the durability requirement for wood to be used in hazard classes.

ENV 1099 Plywood - Biological durability. Guidance for assessment of plywood for use in the different hazard classes.

ENV 12038 Draft 2: 1992. Panel products: method of test for determining the resistance against wood-destroying basidiomycetes of panel products made of or containing wood.

ENV 12038 Durability of wood and wood-based products - Wood-based panels - Method for determining the resistance against wooddestroying basidiomycetes. 